\title{
The level of patients' satisfaction and perception on quality of nursing services in the Renal unit, Kenyatta National Hospital Nairobi, Kenya
}

\author{
James Ndambuki \\ School of Nursing Sciences, The University of Nairobi, Nairobi, Kenya \\ Email: jmutua2005j@yahoo.ca \\ Received 18 January 2013; revised 20 February 2013; accepted 1 April 2013 \\ Copyright (C) 2013 James Ndambuki. This is an open access article distributed under the Creative Commons Attribution License, \\ which permits unrestricted use, distribution, and reproduction in any medium, provided the original work is properly cited.
}

\begin{abstract}
Introduction: Renal failure is on the increase and patients have to identify with renal services and centres where services for renal replacement therapies are rendered. This calls for health care workers to offer services that are perceived as quality and satisfying in order to meet the biophysical and psychological needs of the patients. Study design: This was a descriptive cross-sectional study undertaken at the Renal unit of Kenyatta National Hospital (KNH). Purpose: The study aimed at determining the level of satisfaction and perception of the quality of nursing services in the Renal unit. Methodology: The study population included all patients who were seeking dialysis services during one month period of data collection. The sample size was 151 following data collection. Data collection tools consisted of semi-structured questionnaires which were administered with the aid of research assistants as well as checklists which were self administered. Data analysis and results: Analysis of data was performed using the statistical package of social sciences (SPSS) version 16. Results of data analysis were presented in form of descriptive statistics which included mean, standard deviation and percentages. Regression analysis, t-test and ANOVA were conducted to determine demographic predictors of patient satisfaction with the nursing services. The results of the study revealed that patients in the Renal unit were generally satisfied with the nursing services. The aggregate mean score for all patients on Likert scale was 71.2 out of 105, with a standard deviation of 16.8. Level of satisfaction was $67.8 \%$. The findings also showed that there was no association between demographic characteristics with the levels of satisfaction with the nursing services. Recommendation: The hospital should keep the
\end{abstract}

patients' level of satisfaction high and maintain it through the provision of more dialysis machines and hiring more nurses.

Keywords: Quality Health Care; Patient Satisfaction; Utilization of Nursing Services

\section{INTRODUCTION}

Patients' satisfaction is basic. Services can be regarded or disregarded by patients depending on the ratings they base on.

A study done in Bangladesh showed that the unavailability of doctors and nurses, their negative attitudes and behaviors, lack of drugs, long travelling distances and the waiting times for treatment were major hindrances to the utilization of services in public hospitals [1].

Patient outcomes of care are further affected by rapport and interpersonal quality of practicing professional nurses. The relationship the nurse has with the patient has much impact unlike the outcomes regarding normalizing serum biochemical values. This puts emphasis on the point that the nurse has to achieve therapeutic and humanistic outcomes appropriate for each individual patient [2].

Dissatisfied patients tend to launch complaints to the establishment or seek redress from it more often and dissuade others from seeking health care services from the system if the systems do not favor them [3]. Studies that help to capture the dissatisfaction before patients turn away from seeking healthcare services are important. A survey carried out at $\mathrm{KNH}$ medical wards and Medical Outpatient Clinics (MOPC) on patient satisfaction encompassing different healthcare staff showed that the patients were generally satisfied with the healthcare services [4].

In addition, a survey carried out on patient satisfaction in $\mathrm{KNH}$ pharmacy department in 2009 showed that pa- 
tients were satisfied with the services but reckoned the need for improvement [5]. Though these studies had shown satisfaction with the services offered at the hospital, none had been done on the level of satisfaction with nursing services which are critical in the quality of care a hospital offers prompting a study in the area.

\section{LITERATURE REVIEW}

Review majorly centered on satisfaction level, perception and quality health care, as well as the impact the quality of nursing care has on satisfaction of patients needs.

Several terms were operationalized in line with the objectives of the study. Satisfaction level indicated how comfortable one is with the focused goal that is set [7]. Perception was adopted as the act of apprehending by means of the senses or of the mind, the view of something or event or procedure [8]. Quality health care in this study was expressed at two levels: 1) in view of the patient; 2) in terms of SERVQUAL model of quality care based on five dimensions of the model.

Quality health care is described as the care that fits ones' needs and preferences, does not cause harm, is right for ones illness, and is given without unnecessary delays. Quality healthcare is also the kind of care which includes only the medical tests and procedures one needs, its fair and is not affected by such factors as gender, language, colour, age and income [9]. SERVQUAL model identifies the gap between perception and expectation of customers on the basis of five attributes viz: reliability, responsiveness, assurance, empathy and tangibles to measure consumer satisfaction in light of service quality. SERVQUAL is a service quality framework. The model was refined in early nineties to the useful acronym RATER, i.e., R: Reliability, A: Assurance, T: Tangibles, E: Empathy and R: Responsiveness [10].

\subsection{Patients' Perception and Satisfaction with Quality of Nursing Services in the Renal Unit}

Health care systems today are technically proficient. Strong emphasis is placed on patient service with organized efforts to understand, measure and meet the needs of clients served. Evidence of this phenomenon is found in the numerous publications that focus on patient satisfaction as a key outcome measure of the health care. Patient satisfaction is therefore the perception of patient needs and expectations being met.

Level of satisfaction will vary from person to person and product/service to product/service. The state of satisfaction will depend on a number of both psychological and physical variables which correlate with satisfaction behaviors such as return and recommend rate. Reference [11] suggests that "patient satisfaction may be considered to be one of the desired outcomes of care and that information about patient satisfaction should be as indispensable as assessments of quality”.

Achievement of patient satisfaction can however be hindered by several factors. A study done in Italy showed high level of burnout amongst nephrology nurses and physicians resulted in poor patient satisfaction regarding quality of services offered [12].

In addition, according to reference [13] burnout syndrome among nurses affects patient satisfaction as it affects the quality of nursing care. Burnout predictors for nephrology nurses include inadequate staffing, increased workload and inadequate resources. Further, these burnout predictors are apparent in most health care facilities in Sub-Saharan Africa and could hinder the achievement of satisfaction by patients in the hospitals.

Reference [14], documented quality issues by patients regarding renal nurses’ procedures as for example, "leaving promptly post dialysis” by some Hemodialysis (HD) patients while other HD patients suggested "Commencing dialysis session promptly”.

In South African, patients' satisfaction with quality of care of renal nurses depended upon rapport, personal quality of the nurse and the relationship the nurse had with the patient [2]. In conclusion, the quality of care provided to End Stage Renal Disease (ESRD) patients can be improved through education and a better understanding and appreciation of nursing art [15].

\subsection{Perception \& Satisfaction with Quality of General Nursing Services including Other Related Health Care Services}

Application of high degree of professionalism and skills in the care of patient enables achievement of highest quality of patient care [12]. Reference [16] argues that nursing care features with greater influence on patient satisfaction with healthcare services as compared with other healthcare member interventions. Further Reference [17], indicates that the nurse role includes pre-op teaching, medication administration, record keeping and physical assessment of patients. Implying the practice of nursing in all this aspects could be described as quality nursing care.

Qualities of good nursing have variously been described. For example, oncology patients described attributes of high quality nursing care that contributed to sense of wellbeing. These attributes included: professional knowledge, coordination, partnership, individualization, rapport and caring [18]. To give high quality care, nurses are expected by patients to be kind, joyful, warm, polite, understanding and featuring clinical competence [19].

To offer these quality services, nurses therefore need to be clinically competent. Reference [20], in a study established that clinical competence among nurses in- 
cluded knowing how to give injectables, knowing pharmacodynamics of drugs, knowing when to refer to the doctor and knowing how to handle equipment. Further to these, other attributes have been added. For example, Reference [21] interviewed post operative patients and identified nursing care attributes that led to engagement of patients. These attributes included: open dialogue, recognition of patient as a unique individual, friendly warm personality, giving gentle touch and the availability of the nurse.

Nurses need therefore to understand the strengths and weaknesses of the services they provide to better serve patients' needs [22]. This is because a patient satisfied with care offered, has a chance of seeking care from the same place it was offered and will likely comply with treatment regimes. According to reference [23], nurses need to understand that care cannot be of high quality unless the patient is satisfied. Patient satisfaction should thus remain a requirement for obtaining health care goals [24].

Reference [25] in his review of professional nurse caring found out that patients were concerned about humane treatment as compared with cost and convenience to care. Nursing services and nurse attitudes strongly influenced the satisfaction of the patient.

Reference [26] believes by measuring patient satisfaction, nurses can identify areas in need of improvement in order to affect quality care. Knowing the causes of dissatisfaction and problems encountered in the provision of nursing services especially those that may have been prevented, allows health care workers to focus on areas in need of improvement.

\section{STUDY METHODS}

\subsection{Study Design}

A descriptive cross-sectional study aimed at establishing the level of satisfaction and perception of dialyzing patients on quality of nursing services at KNH's Renal unit was employed.

\subsection{Sample Size Determination}

This was achieved by use of census where all the population was sampled. The sample size was 151 following data collection.

\subsection{Sampling Procedure}

Non-probability purposive sampling was used as the study targeted all patients who were dialyzing and who had the needed information for research investigation.

\subsection{Data Collection Tools}

This Involved use of semi-structured questionnaires and an observation checklist.

\subsection{Data Collection Procedure}

Data was collected by two research assistants who administered the questionnaires to the dialyzing patients. The investigator filled the observation checklist each day for two weeks.

\subsection{Data Analysis and Results Presentation}

Data was analyzed using statistical package for social sciences (SPSS). Results were presented in descriptive statistics. Inferential statistics used, included univariate simple regression, $t$-test and ANOVA. Manual analysis was applied for data on observation checklist.

\subsection{Study Limitations}

1) Study may not have been representative of country since it was conducted in one dialyzing centre in spite of the hospital being the country's national referral hospital.

2) Study generalizability may not be apparent as purposive sampling and use of census were utilized.

\section{STUDY RESULTS}

A univariate linear regression analysis was conducted to determine the socio-demographic predictors of patient satisfaction with nursing services (Table 1).

Table 1. Overall patient satisfaction in relation to socio-demographic factors.

\begin{tabular}{cccc}
\hline Sex & Number $(\mathrm{n})$ & mean & $t$ test/ANOVA \\
\hline Male & 95 & 71.9 & $t=0.76 ; p=0.45$ \\
Female & 54 & 69.9 & \\
\hline Age & & & \\
\hline 13 - 20 years & 9 & 74.2 & $\mathrm{~F}=1.17 ; p=0.32^{*}$ \\
21 - 28 years & 30 & 66.3 & \\
29 - 36 years & 40 & 72.9 & \\
37 - 44 years & 24 & 72.2 & \\
45 - 52 years & 17 & 73.0 & \\
53 - 60 years & 14 & 70.8 & \\
61 - 68 years & 7 & 69.9 & \\
69+ years & 8 & 73.1 & \\
\hline Education level & & & \\
\hline Primary & 19 & 71.5 & $\mathrm{~F}=0.58 ; p=0.63^{*}$ \\
Secondary & 52 & 72.7 & \\
College & 60 & 70.6 & \\
University & 18 & 66.8 & \\
\hline Religion & & 71.2 & \\
\hline Protestant & 83 & 70.1 & \\
Catholic & 52 & 75.8 & \\
Muslim & 5 & & \\
Others & 11 & $70 ; p=0.56^{*}$ \\
\hline
\end{tabular}

*One-way ANOVA test. 
The patient with the minimum score had 32 and the highest score was 105. The mean score was 71.2 with SD of 16.3. The mean satisfaction among male patients was 71.9 which was non-significantly higher than that of female patients ( $t$-test $p$ value $=0.45$ ). There were non significant variations in the mean levels of patient satisfaction in different age groups, education levels and religions. Patients aged $21-28$ years reported the lowest overall satisfaction (mean $=66.3$ ) and those aged 13 - 20 years had the highest satisfaction $($ mean $=74.2$ ), but findings of ANOVA did not show significant associations between age and patient satisfaction with nursing services. Since none of the examined factors was significantly associated with patient satisfaction on the univariate analysis, a multivariable analysis was not conducted.

Sixty-nine (45.7\%) patients reported neutral satisfaction with reception they received during visits to the Renal unit (Table 2).

Most patients reported neutral to satisfied to very satisfied levels with explanations nurses offered for the delays, the way nurses handled complains and generally their attitudes as they attended to patients.

The highest level of dissatisfaction in the Table 3 below was expressed by $19.9 \%$ of patients and was concerned with history taking of previous dialysis and current history of water and dietary intake.

Otherwise most responses related to nursing observations and advice during both pre- and post-dialysis periods showed patients' satisfaction ranged from neutral to satisfied levels.

As pertains to SERVQUAL model of quality, reliability dimension, regarding reliability of the nurse to consult a doctor in case of noticing an abnormal finding on physical exam, was rated highly by 129 (85.3\%) patients who reported neutral to satisfied to very satisfied levels of satisfaction with reliability to report an abnormal finding (Statement 2 of Table 3).

Thirty four patients (22.5\%) reported that they were satisfied with the health education offered by nurses during dialysis (Figure 1).

Thirty seven (24.5\%) had neutral satisfaction with provision of health eduacation. Only $17.9 \%$ of patients were very satisfied with health education.

Table 2. Levels of patient satisfaction with nurse-patient interactions during dialysis at KNH.

\begin{tabular}{|c|c|c|c|c|c|}
\hline \multirow{3}{*}{ Aspect of nurse-patient relationship } & \multicolumn{5}{|c|}{ Level of patient satisfaction with nurses' actions } \\
\hline & Very dissatisfied & Dissatisfied & Neutral & Satisfied & Very satisfied \\
\hline & ${ }^{*} \mathrm{n} / \%$ & ${ }^{*} \mathrm{n} / \%$ & ${ }^{*} \mathrm{n} / \%$ & ${ }^{*} \mathrm{n} / \%$ & ${ }^{*} \mathrm{n} / \%$ \\
\hline Satisfaction with the way nurses' welcome you to the Renal unit & $3(1.2)$ & $25(16.6)$ & $69(45.7)$ & $36(23.8)$ & $18(11.9)$ \\
\hline Nurses explanation for long waiting times and delays & $31(20.5)$ & $18(11.9)$ & $41(27.2)$ & $40(26.5)$ & $21(13.9)$ \\
\hline Handling of complaints regarding nursing services & $28(18.5)$ & $20(13.2)$ & $45(29.8)$ & $35(23.2)$ & $23(15.2)$ \\
\hline Nurses attitudes as they attend to patients & $9(6)$ & $19(12.6)$ & $52(34.4)$ & $39(25.8)$ & $32(21.1)$ \\
\hline
\end{tabular}

"n (frequency)/\% (percentage).

Table 3. Level of patient satisfaction with nursing care provided before and after dialysis at KNH.

\begin{tabular}{|c|c|c|c|c|c|}
\hline & \multicolumn{5}{|c|}{ Level of patient satisfaction with care pre and post dialysis } \\
\hline & Very dissatisfied & Dissatisfied & Neutral & Satisfied & Very satisfied \\
\hline & ${ }^{*} \mathrm{n} / \%$ & ${ }^{*} \mathrm{n} / \%$ & ${ }^{*} \mathrm{n} / \%$ & ${ }^{*} \mathrm{n} / \%$ & "n/\% \\
\hline Nursing observations taken prior to dialysis & $16(10.6)$ & $22(14.6)$ & $47(31.1)$ & $34(22.5)$ & $32(21.2)$ \\
\hline Nursing examination (physical) prior to dialysis & $9(6)$ & $13(8.6)$ & $53(35.1)$ & $41(27.1)$ & $35(23.1)$ \\
\hline $\begin{array}{l}\text { History taking of previous dialysis and current history of water and dietary } \\
\text { intake }\end{array}$ & $30(19.9)$ & $23(15.2)$ & $37(24.5)$ & $36(23.8)$ & $25(16.6)$ \\
\hline $\begin{array}{l}\text { Nurses observations taken post dialysis prior to administering post dialysis } \\
\text { drugs }\end{array}$ & $15(9.9)$ & $18(11.2)$ & $30(19.9)$ & $43(28.5)$ & $45(29.0)$ \\
\hline Do nurses give advice in view of post dialysis results & $16(10.6)$ & $20(13.3)$ & $36(23.8)$ & $45(29.8)$ & $34(22.5)$ \\
\hline $\begin{array}{l}\text { Nurses commitment in facilitating waiving process through NHIF and credit } \\
\text { facilities }\end{array}$ & $12(8)$ & 32 (21.2) & $51(33.8)$ & 23 (15.2) & 33 (21.9) \\
\hline
\end{tabular}

${ }^{*} \mathrm{n}$ (frequency)/\% (percentage). 
According to SERVQUAL model, reassurance dimension rated at $64.9 \%$ from neutral to very satisfied level of health education.

Of all the patients, $90.1 \%$ reported neutral to very satisfied levels with the way the nurses initiated dialysis, $88.3 \%$ with the way the nurses carried out doctors orders,

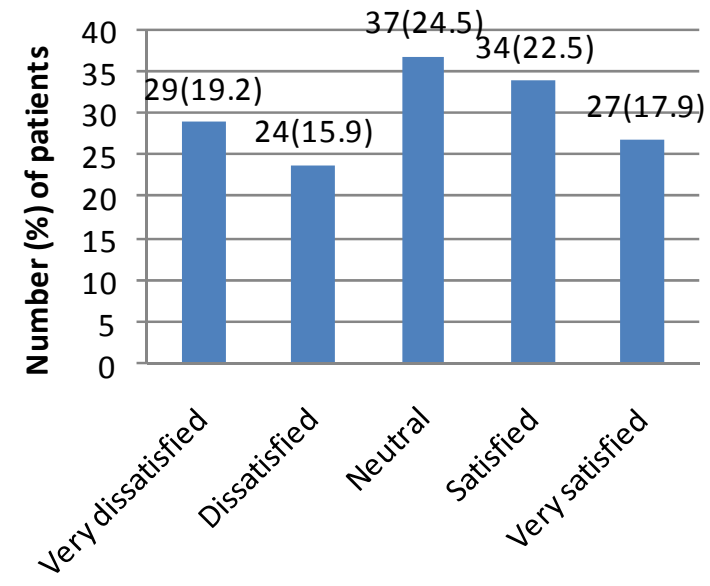

Level of patient satisfaction

Figure 1. Reported levels of patient satisfaction with health education during dialysis.
$85 \%$ with nurses' administration of drugs and $84 \%$ with the way nurses responded to technical hitches during dialysis (Table 4).

Fifty-eight (38.4\%) patients were very satisfied with the dressing of catheter exit site in the Renal unit.

According to SERVQUAL model of quality care, the dimension of responsiveness, in regard to response to alarms by nurses rated $72.9 \%$ by those patients who depicted neutral to satisfied to very satisfied level. This is commendable for this dimension of the model of quality care.

Out of 90 patients who responded to open-ended question, the leading dissatisfaction was by $32.2 \%$ of the patients who reported delays in connecting patients to dialysis machines (Table 5). Second leading cause of dissatisfaction by $23.3 \%$ of the patients regarded understaffing of the Renal unit by nurses. This was followed by inadequate number of dialysis machines as expressed by $22.2 \%$ of patients among other causes.

From Table 6, it is evident from the checklist that machines were seemingly enough for patients for only one day. This is represented by $10 \%$ of the overall results for the item on dialysis machines. This would probably be due to patients moving to other dialysis centres and others had defaulted from treatment that day.

Table 4. Dialysis patients' satisfaction and perception of care during dialysis sessions.

\begin{tabular}{|c|c|c|c|c|c|}
\hline & \multicolumn{5}{|c|}{ Level of patient satisfaction with care pre and post dialysis } \\
\hline & Very dissatisfied & Dissatisfied & Neutral & Satisfied & Very satisfied \\
\hline & ${ }^{*} \mathrm{n} / \%$ & ${ }^{*} \mathrm{n} / \%$ & ${ }^{*} \mathrm{n} / \%$ & ${ }^{*} \mathrm{n} / \%$ & ${ }^{*} \mathrm{n} / \%$ \\
\hline Satisfied with the way nurses initiate dialysis & $7(4.6)$ & $8(5.3)$ & $58(38.4)$ & $41(27.2)$ & $37(24.5)$ \\
\hline $\begin{array}{l}\text { Perception of monitoring of dialysis by nurses in regard to responding to } \\
\text { alarms and patient needs }\end{array}$ & $19(12.6)$ & $22(14.6)$ & $49(32.5)$ & $37(24.5)$ & $24(15.9)$ \\
\hline Nurses response during technical hitch or alarm failure & $14(9.3)$ & $10(6.6)$ & $36(23.8)$ & $42(27.8)$ & $49(32.5)$ \\
\hline Administration of medication by nurses during dialysis & $9(6)$ & $13(8.6)$ & $45(29.8)$ & 39 (25.8) & 45 (29.8) \\
\hline $\begin{array}{l}\text { Nurses' enquiry to physician for corrective changes in case results of kidney } \\
\text { function tests are found abnormal }\end{array}$ & $6(4)$ & 22 (14.6) & 57 (37.8) & $41(27.2)$ & 25 (16.6) \\
\hline $\begin{array}{l}\text { Satisfaction with the way catheter sites and wounds are dressed by nurses and } \\
\text { adherence to protocol recommendations in dressing catheter exit site and }\end{array}$ & $13(8.6)$ & $11(7.3)$ & $26(17.2)$ & 43 (28.5) & $58(38.4)$ \\
\hline Carrying out of doctors orders by nurses & $7(4.6)$ & $11(7.3)$ & $41(27.2)$ & 49 (32.6) & $43(28.5)$ \\
\hline
\end{tabular}

*n (frequency)/\% (percentage).

Table 5. Patient reported causes of dissatisfaction with nursing services in the Renal unit.

\begin{tabular}{ccc}
\hline & Frequency (n) & Percent (\%) \\
\hline Identified cause of dissatisfaction & & \\
Delays in connecting dialysis machines & 29 & 32.2 \\
Inadequate number of nursing staff & 21 & 23.3 \\
Inadequate number of dialysis machines & 20 & 22.2 \\
Unfavourable attitude towards patients & 13 & 14.4 \\
Lack of adequate monitoring & 12 & 13.3 \\
Poor nurse-patient communication & 10 & 11.1 \\
Inadequate supplies & 3 & 3.3 \\
\hline
\end{tabular}


Table 6. Observation checklist.

\begin{tabular}{|c|c|c|c|c|}
\hline \multicolumn{5}{|l|}{ Part (a) } \\
\hline \multirow{2}{*}{$\begin{array}{l}\text { ITEMS/QUESTIONS } \\
\text { (a) EQUIPMENT }\end{array}$} & \multicolumn{4}{|c|}{ AVAILABILITY } \\
\hline & \multicolumn{2}{|c|}{ DAYS (YES) } & DAYS (NO) & FINAL SCORE (\%) \\
\hline 1) Are there enough dialysis machines? & & & 9 & $10 \%$ \\
\hline 2) Are the available dialysis machines repaired in time? & & & 2 & $80 \%$ \\
\hline 3) Are there enough peritoneal fluid bags for peritoneal dialysis? & & & 4 & $60 \%$ \\
\hline $\begin{array}{l}\text { 4) Are there enough dialysis items for hemodialysis patients in the items store? } \\
\text { (e.g. blood lines, dialyzers, bicarbonate soln., \& dialysate) }\end{array}$ & & & 2 & $80 \%$ \\
\hline $\begin{array}{l}\text { 5) Are peritoneal dialysis items available in the dialysis store? } \\
\text { (PD catheter, transfer sets) }\end{array}$ & & & 4 & $60 \%$ \\
\hline $\begin{array}{l}\text { 6) Are miscellaneous clinical items always available to facilitate dialysis? } \\
\text { (e.g. dressing packs, disinfectant lotions, and priming isotonic solution, gauzes) }\end{array}$ & & & 1 & $90 \%$ \\
\hline \multicolumn{5}{|l|}{ Part (b) } \\
\hline (b) OTHER HEALTH CARE STAFF & & DAYS (YES) & DAYS (NO) & FINAL SCORE (\%) \\
\hline 1) Is the nurse-patient ratio appropriate? & & 2 & 8 & $20 \%$ \\
\hline 2) Are the nephrologists and doctors enough and available for treatment and prescril & & 9 & 1 & $90 \%$ \\
\hline 3) Are there enough biomedical technologists for repair and disinfection of dialysis & chines? & 10 & 0 & $100 \%$ \\
\hline $\begin{array}{l}\text { 4) Are lab technologists available to facilitate kidney function tests and other releva } \\
\text { investigations in the unit? }\end{array}$ & & 10 & 0 & $100 \%$ \\
\hline 5) Are nutritionists available for dietary prescription and counseling? & & 8 & 2 & $80 \%$ \\
\hline 6) Is there a renal counselor assigned for patients? & & 10 & 0 & $100 \%$ \\
\hline 7) Are there supportive staff to aid in environmental clean up? & & 10 & 0 & $100 \%$ \\
\hline
\end{tabular}

Part (b) of the checklist reveals the nurse patient ratio as poor as there were only 2 days (20\%) when the ratios were somehow appropriate. This would have been attributed to new nurses or visiting students being conversant with procedures after a few days in which they could improve and boost the workload. Other items and staff were generally available as these are represented by availability for 7 days (70\% availability).

\section{DISCUSSION}

From the main findings, patients' satisfaction and perception of nursing services have been rated in terms of percentages and as scores on a Likert scale. Parametric tests such as linear regression, $t$-tests and ANOVA were carried out to determine possibility of demographic predictors of patient satisfaction and perception with the nursing services.

The ratings of level of patients' satisfaction with the nursing services reflect quality of nursing services as highlighted from the literature review.

According to Reference [26], quality health care is the care that: fits ones' needs and preferences, includes only the medical tests and procedures one requires, and is not affected by gender, colour and language. In addition, a quality health measure is information from a patient's record that is converted into a rate, percentage or time.
Thus according to patients' response on satisfaction, the level of the score reflected the quality of the nursing services.

Apart from patients' view of quality health care, quality was also measured using SERVQUAL model which incorporates five dimensions. Three dimensions utilized in this study included responsiveness, reliability and reassurance [10].

Level of satisfaction and perception of patients regarding nursing services was rated on Likert scale of 1 5 from the matrix questions raised pertaining to nursing services.

According to Dr. Watson's carative factor number four, the strongest tool in establishing helping-trust relationship, is the mode of communication which creates rapport and caring.

The research findings reveal 123 (81.4\%) patients were satisfied with the reception they had during visits to the Renal unit. This translates to satisfaction level of 3.27 on average out of 5 on Likert scale for all 151 sampled patients. These findings are consistent with carative factor four of Dr. Watson mode communication. The manner of welcoming patients in the Renal unit created rapport that led to acceptability of nursing care services.

Reference [11] described patient satisfaction as a desired outcome of provided care and that quality of care 
was reflected by judgment of degree of satisfaction.

Reference [11] description is supported by the research findings in which 88 (58.3\%) patients and 79 (52.3\%) patients featured satisfied to very satisfied levels with post dialysis observations and advice, respectively. The two post dialysis nursing services (observations and advice) had high degree of patient satisfaction which translated into high quality care in regard to the patients.

Care of patients during dialysis was generally ranked high on the Likert scale scores, meaning, it was ranked as high quality in the face of the patients. Iniating dialysis measured 3.62, alarm attendance (3.17), nurses inquiry to physicians for corrective changes (3.38), carrying out doctors orders (3.73) and satisfaction with dialysis catheter and general wound dressing was rated at 3.81, which was the highest score on Likert scale by $76.2 \%$ of the patients. General care of patients during dialysis was of high quality as patients were very satisfied. This aspect is supported by Reference [24], in which quotes "Care cannot be of high quality unless the patient is satisfied".

Nurses' attitude rated 3.43 on Likert scale for all 151 patients on dialysis. Most patients reported neutral to satisfied level of satisfaction as regarded attitude by nurses as they performed their nursing services. Reference [25] indicated that nursing services and nurse attitudes strongly influence the satisfaction of the patient. Patients were concerned about humane treatment as compared with cost and convenience of care.

Nursing care was also rated by SERVQUAL model of measuring service quality but on three dimensions of reassurance, responsiveness, and reliability. Reliability of the nurse to consult a doctor on noticing abnormal finding in physical exam, rated $85.3 \%$ by all patients whose satisfaction was neutral to satisfied to very satisfied lev els. Responsiveness dimension also scored high (72.9\%) in the face of the nurse responding to alarms of the dialysis machines and this response was sum up of patients with neutral to satisfied to very satisfied levels. The dimension of reassurance was applied to health education in which case $64.9 \%$ was the percentage of all patients who depicted neutral, satisfied to very satisfied level with reassurance during health education. Thus quality was apparent with the three dimensions of SERVQUAL model. This depicted that services in the Renal unit were of high quality in regard to this SERVQUAL model of quality care.

In the open ended question (non-structured), 90 patients $(59.6 \%)$ of the 151 respondents stated at least one cause of their dissatisfaction with the nursing services in the Renal unit. Patients were most commonly dissatisfied with reported delays with connection to dialysis machines. $32.2 \%$ of the 90 patients mentioned delays and felt that these delays were amenable to nurses acting with urgency. This concurred with reference [13] findings on predictors of burnout among nurses implying similar circumstances when it comes to the factors to burnout in spite of the settings.

Dissatisfaction was expressed in understaffing of nurses and inadequate number of dialysis machines by $23.3 \%$ and $22.2 \%$ of patients, respectively.

According to results obtained from the observation checklist on staffing and accessories (items) in the Renal unit, the then nurse-patient ratio was inappropriate and there were no adequate dialysis machines. Out of 10 days of collection of data with the observation checklist, machines seemed to be adequate for 1 day (10\%) as this day patient turnout was low and seemingly others had gone to other dialysis centres in Nairobi environs. The nursepatient ratio was satisfactory for 2 out of the ten days of filling the checklist and this was probably due to students who had been used to renal procedures and who eased much of the workload. The poor nurse-patient ratio and inadequate number of dialysis machines was in agreement with the responses of subjects in the open-ended questions.

As pertained to the matter of improving nursing services, $33.3 \%$ of the 90 patients (who responded to openended question on improving nursing services) felt the area that required urgent improvement was availing of more dialysis machines, followed by hiring of additional nurses (27.8\% of patients). These findings on improvement were commensurate with the shortcomings expressed in the checklist. In other words, what was found as lacking from the checklist was cited blindly as a requirement for improvement of the nursing services. This meant data collection was consistent in both tools.

In a nutshell, the checklist featured optimal staffing of the general healthcare staff (apart from nurses) and adequacy of dialysis items (except dialyzing machines) as featured by higher percentages of days of availability of the items at the time of filling the observation checklist.

In summing up the findings, overall satisfaction was measured. Patients were generally satisfied with the quality of services offered by nurses in the Renal unit at Kenyatta National Hospital.

\section{CONCLUSIONS}

From the study's findings, it was concluded that patients were generally satisfied with the quality of nursing services in the Renal unit as overall satisfaction was 3.39 out of 5 on the Likert scale (71.2 mean score out of 105 total score on Likert scale). This was $67.8 \%$ level of satisfaction. It was also found that patients who attended twice weekly dialysis were 72 , a reflection of $47.7 \%$ of the total population. An attendance that was fair enough as it controlled the uremic syndromes and also showed 
the patients' desire to come back for the same treatment a predictor for level of satisfaction. Patients reported the leading causes of dissatisfaction with nursing services as an inadequate number of dialysis machines and inappropriate nurse-patient ratio in the Renal unit. Use of the SERVQUAL model depicted nursing services in the rental unit as quality on dimensions of responsibility, reliability and reassurance.

\section{RECOMMENDATIONS}

The hospital requires to equip the Renal unit with more dialysis machines to raise the levels of patients' perception and satisfaction with nursing services/health care services in general.

Retention and improvement of nurse staff levels are required to boost satisfaction and speed of the nursing services delivery.

\section{ACKNOWLEDGEMENTS}

I wish to extend my sincere gratitude to the Kenyatta National Hospital administration for giving me an opportunity to further my studies. Great thanks go to, The Chief Executive Officer of Kenyatta National Hospital for allowing me to conduct this research at the hospital.

Thanks to all patients attending the Renal unit of Kenyatta National, hospitals who participated in the study. I know how tasking this is especially because of the sickness, but thank you for finding time towards completing the questionnaires.

Special thanks go to my research assistants who ensured that questionnaires were distributed and returned accordingly. Finally, thanks to my statistician Mr. Phillip Ayieko for his assistance in data analysis.

\section{REFERENCES}

[1] HEU (2003) Bangladesh National Health Accounts 19992000. Dhaka: Health economics unit, ministry of health and family welfare, government of Bangladesh, 63-71.

[2] Department of Nursing Science (2000) Nephrology nursing: Nursing dynamics. University of Port Elizabeth, Port Elizabeth.

[3] Nyer, P. (1999) Cathartic complaining as a means of reducing consumer dissatisfaction. Journal of Consumer Dissatisfaction, Dissatisfied and Complaining Behavior, 12, 15-25.

[4] Nursing Research Committee (2007) Customer satisfaction survey in medical wards and medical outpatient clinics. Kenyatta National Hospital, Nairobi.

[5] Pharmacy Department (2009) Customer care satisaction in pharmacy department. Research study conducted in pharmacy department. Kenyatta National Hospital, Nairobi.

[6] Kapusia (2005) Customer care in Renal unit. Research study conducted in Renal unit. Kenyatta National Hospital, Nairobi.

[7] Dennisgorelik.com (2011) Satisfaction level.
http://www.dennisgorelik.com/ai/SatisfactionLevel.htm

[8] Dictionary.com (2011) Perception. http://dictionary.reference.com

[9] Wisconsin Hospital Association (2004) What is quality health care? http://www.wicheckpoint.org

[10] Parasuraman, A., Zeitham, V.A. and Berryl, L.L. (1988) SERVQUAL: A multiple-item scale for measuring consumer perceptions of service quality. Journal of Retailing, 64, 12-40.

[11] Donabedian, A. (1988) The quality of care: How can it be assessed? Journal of the American Medical Association, 260, 1743-1748. doi:10.1001/jama.1988.03410120089033

[12] Argentero, P., Dell’Olivo, B. and Ferreti, M.S. (2008) Staff burnout and patient satisfaction with the quality of dialysis care. American Journal of Kidney Diseases, 51, 80-92. doi:10.1053/j.ajkd.2007.09.011

[13] Flynn, L., Thomas-Hawkins, C. and Clarke, S.P. (2009) Organizational traits, care processes and burnout among chronic hemodialysis nurses. Western Journal of Nursing Research, 31, 569-582. doi:10.1177/0193945909331430

[14] Willis, C.E., Watson, J.D., Casson, K., Doherty, C.C., Telford, A.M. and Brown, J.H. (1998) Locations for renal services patients' satisfaction surveys. The Ulster Medical Journal, 67, 110-114.

[15] Armistead, N.C. (2005) Communicating for quality: In service training modules. Nephrology Nursing Journal, 32, 531.

[16] Oberst, M.T. (1984) Patients’ perceptions of care: Measurement of quality and satisfaction. Imprint, 53, 23662373.

[17] Tworek, P.M. and Kim, J. (1981) Nursing in the cardiac catheterization laboratory: One hospital's procedure. Critical Care Quarterly, 4, 83-88.

[18] Radwin, L. (2000) Oncology patients' perceptions of quality nursing care. Research Nursing Health, 23, 179-190. doi:10.1002/1098-240X(200006)23:3<179::AID-NUR2> 3.0.CO;2-T

[19] Wysong, P.R. and Driver, E. (2009) Patients' perceptions of nurses' skill. Critical Care Nurse, 29, 24-37. doi:10.4037/ccn2009241

[20] Baldorsdottir, G. and Jonsdottir H. (2002) The importance of nurse caring behaviors as perceived patients receiving care at an emergency department. Heart Lung, 31, 67-75. doi:10.1067/mhl.2002.119835

[21] Kralik, D., Koch, T. and Wotton K. (1997) Engagement and detachment: Understanding patients' experiences with nursing. Journal of Advanced Nursing, 26, 399-407. doi:10.1046/j.1365-2648.1997.1997026399.x

[22] Taylor, S.A. (1994) Distinguishing service quality from patient satisfaction in developing healthcare marketing strategies. Hospital and Health Service Administration, 39, 221-236.

[23] Cleary, P.D., Keroy, L., Karapanos, G. and Mullen, W. (1989) Patient assessment of hospital care. Quality Review Bulletin, 15, 172-179.

[24] Vuori, H. (1987) Patient satisfaction-An attribute or 
indicator of the quality of care? Quality Review Bulletin, 13, 106-108.

[25] Valentine, K. (1997) Exploration of the relationship between caring and cost. Holistic Nursing Practice, 11,
71-81.

[26] Gillette, V.A. (1995) Elderly patients and family members' satisfaction with discharge planning. University of South Mississippi, Mississippi. 